\title{
Catching up to the technology frontier: the dichotomy between innovation and imitation
}

\author{
Jakob B. Madsen, Md. Rabiul Islam, and James B. Ang \\ Department of Economics, Monash University
}

Abstract. Using data for 55 developing and developed countries, this research examines the roles of technology transfer, research intensity, educational attainment, and the ability to absorb foreign technology in explaining cross-country differences in productivity growth. The results show that innovation is an important factor for growth in OECD countries, whereas growth in developing countries is driven by imitation. Furthermore, the interaction between educational attainment and the distance to the frontier is a significant determinant of growth in the overall sample. JEL classification: O30, O40

Se rapprocher de la frontière technologique: la dichotomie entre innovation et imitation.. A l'aide de données pour 55 pays développés et en développement, on examine les rôles du transfert de technologie, de l'intensité de recherche, du niveau d'éducation, et de l'habileté à absorber la technologie étrangère dans l'explication des écarts entre pays dans la croissance de la productivité. Les résultats montrent que l'innovation est un facteur important dans la croissance des pays de l'OCDE alors que la croissance des pays en développement est animée par l'imitation. De plus, l'interaction entre le niveau d'éducation et la distance de la frontière est un facteur déterminant et significatif de la croissance dans tout l'échantillon.

\section{Introduction}

Endogenous growth theory has increasingly focused on the roles of technology transfer and absorptive capacity in explaining productivity growth across countries (Eaton and Kortum 1999; Howitt 2000; Xu 2000; Keller 2002a, b; Griffith, Redding, and Van Reenen 2003, 2004; Hu, Jefferson, and Jinchang 2005; Kneller 2005; Kneller and Stevens 2006; Madsen, Saxena, and Ang 2009). Countries that are technologically backward may have greater potential for growth than more

Email: james.ang@buseco.monash.edu.au

Canadian Journal of Economics / Revue canadienne d'Economique, Vol. 43, No. 4 November / novembre 2010. Printed in Canada / Imprimé au Canada

0008-4085 / 10 / 1389-1411 / ${ }^{\circ}$ Canadian Economics Association 
advanced countries (Gerschenkron 1962), mainly because of their lower effective costs in creating new and better products (Howitt 2000). However, backwardness does not automatically translate into higher growth. First, given that technological knowledge is tacit, adaptors need to spend time and resources to master the technologies that are developed elsewhere (Howitt 2005). Second, the increasing complexity of products requires a large investment in knowledge in order to take advantage of the technology developed elsewhere (Howitt 2005). Third, factory workers, technicians, engineers, and managers cannot adapt new technologies without adequate training (Hobday 2003).

This research explores the effects of R\&D intensity, educational attainment, distance to the technological frontier, and their interactions on TFP growth in developed and developing countries. Specifically, we test the importance of research and education in creating new knowledge or in imitating technologies that are developed elsewhere. This provides some insights into whether investments in $\mathrm{R} \& \mathrm{D}$ and education have resulted in more innovative or imitative activity. Despite the importance of these issues for growth in developing countries, empirical studies on the effects of the interaction between distance to the frontier and $\mathrm{R} \& \mathrm{D}$ intensity or educational attainment have focused exclusively on OECD countries (e.g., Griffith, Redding, and Van Reenen 2003, 2004; Kneller 2005; Kneller and Stevens 2006), which is probably because of the difficulty associated with obtaining $R \& D$ data for developing countries.

Developing countries that are far from the technological frontier may derive more benefits from investment in knowledge than OECD countries. By acquiring foreign technology, they may be able to obtain additional economies of scale through leapfrogging over the early stages of development (Gerschenkron 1962). As shown by Coe, Helpman, and Hoffmaister (1997), TFP in developing countries is positively and significantly related to international R\&D spillovers from advanced economies. Moreover, Savvides and Zachariadis (2005) argue that TFP growth for developing countries that are relatively close to the frontier is likely to be significantly boosted by technological diffusion from the frontier countries. These insights suggest that more attention should be paid to the roles played by R\&D and educational attainment for growth in developing countries.

The term 'absorptive capacity' captures the idea that the benefit of technological backwardness enjoyed by a laggard country can be enhanced if it is sufficiently capable of exploiting the technology developed in the frontier countries (Abromovitz 1986). Although countries may be endowed with different abilities in adopting new technologies, more investment in domestic R\&D and education may generally increase their capacity to effectively absorb foreign technology. Hobday (2003) shows that a common factor behind the success of the NICs was large investment in training and $\mathrm{R} \& \mathrm{D}$ in order to adapt those technologies that were developed in more advanced countries.

New technology is often complex and is embedded in physical capital that creates significant interdependence between the leader and follower countries. Effective transfer of foreign technology may be hindered unless the 
follower countries undertake adequate local R\&D investments so that knowledge developed in the frontier countries can be appropriately adapted to local conditions (Verspagen 1991; Fagerberg 1994; Aghion and Howitt 2005; Howitt 2005). Furthermore, higher educational attainment by the work force may also facilitate the assimilation of foreign technology (Nelson and Phelps 1966; Abromovitz 1986; Cohen and Levinthal 1989; Benhabib and Spiegel 1994, 2005; Engelbrecht 1997). These investments are essential for the laggards to upgrade their technology, move up the development ladder, and catch up to the frontier. Hence, R\&D and educational attainment have two facets with respect to the production of knowledge - a direct effect and an indirect effect through enhancing the ability to absorb new technology (Kneller and Stevens 2006).

The paper is structured as follows. Section 2 briefly discusses the analytical framework that is used to guide our empirical formulation. Section 3 discusses the data and construction of the variables. The empirical estimates are obtained using the system GMM estimator for a panel of 55 countries covering the period 19702004. The sample is further divided into 23 OECD and 32 developing countries to gain some insights into the importance of $R \& D$, educational attainment, and absorptive capacities for TFP growth in laggard economies relative to advanced ones. The results are presented and discussed in section 4 and robustness checks are undertaken in section 5. Section 6 concludes.

\section{Empirical framework}

The empirical analysis in this paper integrates the hypothesis of Nelson and Phelps (1966), which focuses on the interaction between educational attainment and distance to the frontier, with that of Howitt (2000) and Griffith, Redding, and Van Reenen $(2000,2003)$, in which research intensity and its interaction with distance to the frontier play the key roles for growth.

First, consider the following equation that characterizes the relationship between educational attainment $(S C H)$ and TFP growth $\left(\dot{A}_{t} / A_{t}\right)$, as postulated by Nelson and Phelps (1966). In their model, TFP growth is an increasing function of the interaction between educational attainment and the gap between the theoretical level of technology $\left(T_{t}\right)$ and the technology in practice $\left(A_{t}\right)$ :

$$
\frac{\dot{A_{t}}}{A_{t}}=\phi\left(S C H_{t}\right)\left(\frac{T_{t}-A_{t}}{A_{t}}\right) . \quad \phi(0)=0, \quad \phi^{\prime}(S C H)>0 .
$$

By allowing the gap between the actual and theoretical level of technology to influence TFP growth with a time lag, the empirical counterpart of this equation can be written as follows (Benhabib and Spiegel 1994):

$$
\frac{\dot{A_{t}}}{A_{t}}=\phi\left(S C H_{t}\right)\left(\frac{A_{t-1}^{\max }}{A_{t-1}}\right)
$$


where $A^{\max }$ is TFP at the technology frontier country. This equation shows that the further a country is behind the technological frontier, the higher is its growth potential, provided that it has a sufficiently high level of educational attainment, or absorptive capacity, to take advantage of its backwardness. This reasoning follows the seminal hypothesis of Gerschenkron (1962) that backward countries possessing an educated labour force are able to take advantage of the technology developed elsewhere to catch up to the frontier. Similarly, Easterlin (1981) notes that more productive nations have used the same technology throughout history and that Japan modernized in the Meiji restoration period using western technology, suggesting that personal contacts and the availability of an educated workforce to understand new technologies have been essential for the assimilation of foreign technology. Thus, given that technology must be taught and learned, education becomes an integral part of its transfer. In other words, it is simply easier for an educated rather than an uneducated labour force to master new technologies that have been developed elsewhere.

Based on the insights from Schumpeterian growth models, the important roles of innovation and assimilation of foreign technology for growth have been further highlighted by Howitt (2000) and Griffith, Redding, and Van Reenen (2003). They demonstrate that domestic R\&D activity, in addition to stimulating TFP growth, facilitates technology transfer. They suggest that the following specification is appropriate for testing for the influence of $R \& D$ on growth:

$$
\frac{\dot{A_{t}}}{A_{t}}=\alpha\left(\frac{X}{Q}\right)_{t-1}+\beta \ln \left(\frac{A^{\mathrm{max}}}{A}\right)_{t-1}+\chi\left(\frac{X}{Q}\right)_{t-1} \ln \left(\frac{A^{\mathrm{max}}}{A}\right)_{t-1},
$$

where $X$ is $\mathrm{R} \& \mathrm{D}, Q$ is product variety and $(X / Q)$ is research intensity.

This Schumpeterian model maintains the scale effects that are present in the first-generation endogenous growth models. However, it deviates from them by allowing for product proliferation effects to overcome Jones's critique. Jones $(1995 \mathrm{a}, \mathrm{b})$ shows that the increasing number of scientists and engineers engaged in R\&D in the US since the 1950s has not been followed by a concomitant increase in TFP growth rates, thus refuting the first-generation R\&D-based endogenous growth models of Romer (1990) and Aghion and Howitt (1992). To address this problem, the Schumpeterian models of Aghion and Howitt (1998) and Howitt (2000) assume that the effectiveness of R\&D is diluted due to the proliferation of products as the economy expands. Thus, growth can still be sustained if $\mathrm{R} \& \mathrm{D}$ is kept at a fixed proportion of the number of product lines, which is, in turn, proportional to the size of the population along the balanced growth path.

Considering the joint effects of educational attainment and R\&D, eqs (2) and (3) yield the following empirical specification, which is augmented to allow for 
the direct effects of educational attainment and several control variables:

$$
\begin{aligned}
\Delta \ln A_{i t}= & \beta_{0 i}+\beta_{1} \ln \left(\frac{X_{i t}}{Q_{i t}}\right)+\beta_{2} \ln \left(\frac{A_{t-1}^{\max }}{A_{i, t-1}}\right)+\beta_{3}\left(\frac{X_{i t}}{Q_{i t}}\right) \ln \left(\frac{A_{t-1}^{\max }}{A_{i, t-1}}\right) \\
& +\beta_{4} \ln S C H_{i t}+\beta_{5} S C H_{i t} \ln \left(\frac{A_{t-1}^{\max }}{A_{i, t-1}}\right)+\gamma^{\prime} C_{i t}+\varepsilon_{i t},
\end{aligned}
$$

where $C$ is a vector of control variables (which includes growth in trade openness, growth in FDI inflows as a percentage of nominal GDP, change in the rate of inflation, growth in financial development, and distance from the equator) and $\varepsilon_{i t}$ is a stochastic error term. Three different measures of research intensity are used and discussed in the next section. Schooling $(\mathrm{SCH})$ is included as an additional regressor, following Benhabib and Spiegel's (1994) extension of the Nelson-Phelps model.

These are considered to be the most important control variables in crosscountry growth studies (Fischer 1993; Andrés and Hernando 1997). Trade openness is assumed to influence growth positively because it indicates, among other things, low-tariff and non-tariff trade barriers, increasing competition, and the potential to acquire knowledge that is embedded in imported goods (Madsen 2009). Foreign direct investment is assumed to be growth enhancing because of the potential positive externalities that are associated with the technologies, know-how, and knowledge that are embodied in foreign investment (Savvides and Zachariadis 2005; Keller 2004). Inflation is bad for growth because it tends to increase required capital returns, which in turn lowers investment in R\&D and fixed capital (Madsen and Davis 2006). Furthermore, rising inflation is often an indication of macroeconomic mismanagement (Fischer 1993; Andrés and Hernando 1997). Growth is often assumed to be positively related to financial development, as easier access to credit enables the initiation of capital-intensive projects and provides funding of R\&D (Aghion, Howitt, and Mayer-Foulkes 2005; Ang and McKibbin 2007).

Finally, a greater distance from the tropics is often considered to be positively related to growth because of a more favourable climate, higher endowment of natural resources, the absence of tropical diseases, and shorter geographic distances to the technology frontier (Rodrik, Subramanian, and Trebbi 2004).

\section{Data, graphical evidence, and estimation method}

The above model is estimated in five-year differences, to filter out random and cyclical fluctuations, using annual data over the period 1970-2004 for a panel of 55 countries ( 23 OECD countries and 32 developing countries). The countries included in the sample are listed in the notes to table 1 . The country sample has been made as large as possible to make the regressions as inclusive as possible. The criteria for inclusion are that the country has at least 8 annual observations 
TABLE 1

Descriptive statistics (1970-2004)

\begin{tabular}{|c|c|c|c|c|c|c|}
\hline & $\Delta \ln A$ & $A^{U S} / A$ & $N / L$ & $R / Y$ & $P / L$ & $S C H$ \\
\hline \multicolumn{7}{|c|}{ Total sample (55 countries) } \\
\hline Mean & 0.90 & 252.36 & 0.23 & 0.99 & 0.04 & 6.11 \\
\hline Std Dev. & 1.96 & 187.98 & 0.26 & 0.84 & 0.07 & 2.88 \\
\hline Minimum & -7.04 & 100.00 & 0.00 & 0.01 & 0.00 & 0.28 \\
\hline Maximum & 7.42 & 1351.06 & 1.52 & 3.97 & 0.54 & 12.29 \\
\hline Observations & 385 & 385 & 370 & 296 & 326 & 384 \\
\hline \multicolumn{7}{|c|}{ OECD countries (23) } \\
\hline Mean & 1.23 & 139.67 & 0.45 & 1.57 & 0.07 & 8.59 \\
\hline Std Dev. & 1.25 & 30.06 & 0.25 & 0.77 & 0.09 & 1.96 \\
\hline Minimum & -1.72 & 100.00 & 0.05 & 0.18 & 0.00 & 2.65 \\
\hline Maximum & 5.84 & 310.45 & 1.52 & 3.97 & 0.54 & 12.29 \\
\hline Observations & 161 & 161 & 160 & 154 & 159 & 160 \\
\hline \multicolumn{7}{|c|}{ Developing countries (32) } \\
\hline Mean & 0.67 & 333.36 & 0.05 & 0.36 & 0.00 & 4.34 \\
\hline Std Dev. & 2.32 & 210.82 & 0.04 & 0.22 & 0.01 & 1.98 \\
\hline Minimum & -7.04 & 126.59 & 0.00 & 0.01 & 0.00 & 0.28 \\
\hline Maximum & 7.42 & 1351.06 & 0.26 & 1.08 & 0.04 & 8.68 \\
\hline Observations & 224 & 224 & 210 & 142 & 167 & 224 \\
\hline
\end{tabular}

NOTES: All data are expressed in percentages, except $S C H$, which is expressed in years. OECD countries include Australia, Austria, Belgium, Canada, Denmark, Finland, France, Germany, Greece, Iceland, Ireland, Italy, Japan, Korea, Netherlands, New Zealand, Norway, Portugal, Spain, Sweden, Switzerland, the United Kingdom, and the United States. Developing countries include Argentina, Bolivia, Brazil, Chile, Colombia, Costa Rica, Ecuador, Egypt, Guatemala, India, Indonesia, Iran, Malaysia, Mauritius, Mexico, Niger, Pakistan, Panama, Paraguay, Peru, the Philippines, Rwanda, Senegal, South Africa, Sri Lanka, Sudan, Thailand, Tunisia, Turkey, Uruguay, Venezuela, and Zambia. All the data are measured in five-year intervals. The growth rates are annualized.

of $R \& D$ spanning at least 20 years. The sample contains a wide cross-section of countries with different per capita income levels, including most OECD countries and developing countries such as Niger, Peru, Senegal, Sudan, and Thailand.

Although the data are in five-year differences, the regression approach suggested by Basu, Fernald, and Kimball (2006) is used to ensure that all business cycle influences are filtered out. This method involves regressing income growth against input growth and cyclical changes in hours worked. Since the growth in weekly hours worked captures the influence of the business cycle on output, the residual can be interpreted as the trend growth in TFP. We use cyclical labour productivity measure as the growth in labour productivity instead of weekly hours worked, given that weekly hours worked are available mainly for OECD countries only. Furthermore, growth in weekly hours worked cannot be used as a cyclical indicator for most OECD countries because it has shown a significant declining trend during the period 1970-2004. This reduction has not been gradual but rather reflects changes in working hour regulations, such as going from a six- to a five-day week. Moreover, the work week has often been permanently reduced following economic downturns, thus rendering it difficult to separate the 
trend from the cycle. The US, which is the country considered by Basu, Fernald, and Kimball (2006), is one of the very few OECD countries in which weekly hours worked have fluctuated around a constant level over the last four decades. TFP is recovered as the residual, $z$, from the following panel OLS regression:

$$
\Delta \ln (Y / L)_{i t}=\kappa_{0}+\kappa_{1} \Delta \ln (K / L)_{i t}+\kappa_{2} \Delta^{2} \ln (Y / L)_{i t}+d z_{i t},
$$

where $\Delta^{2}$ signifies second differences. Here, $L$ is labour input measured by the labour force or the labour force multiplied by annual hours worked for the countries for which annual hours are available (OECD countries), and $K$ is the capital stock and is measured using the perpetual inventory method. The initial capital stock is estimated using the Solow model steady-state value of $I_{0} /(\delta+g)$, where $I_{0}$ is initial real investment, $\delta$ is the rate of depreciation, which is assumed to be 5\% following Bosworth and Collins (2003), and $g$ is the average geometric growth rate in real investment over the period 1970-2004. These data are obtained from the Penn World Table.

The following three indicators are used to measure R\&D intensity $(X / Q)$ (see Ha and Howitt 2007; Madsen 2008b; Madsen, Saxena, and Ang 2009): (1) the ratio of R\&D scientists and engineers to the total labour force $(N / L)$; (2) the share of R\&D expenditures in GDP $(R / Y){ }^{1}$ and (3) the number of patent applications filed by domestic residents relative to the total labour force $(P / L)$. Patent applications are used in preference to patents granted, since the frequency of patent granting activities varies over time and across countries (Griliches 1990; Jaffe and Palmer 1997).

$\mathrm{R} \& \mathrm{D}$ data are collected from various issues of the UNESCO Statistical Yearbook and patent data are obtained from the WIPO (2007). Some missing data between years are interpolated arithmetically. The distance to the frontier $\left(A^{\max } / A\right)$ is measured by the labour productivity gap in purchasing power parities between the US and the country under consideration. To mitigate the effects of the strong multicollinearity between distance to frontier and research intensity/human capital and their interactions, we use the TFP gap between the technology leader and the country under consideration as a measure of the distance to the frontier for the two interaction terms.

Educational attainment $(\mathrm{SCH})$ is measured by the average years of schooling of the population aged 25 and over using the data set provided by Barro and Lee (2001). Trade openness (TO) is measured as the sum of exports and imports over GDP using data from WDI (2007). Data for foreign direct investment are taken from the IMF (2007). The rate of inflation is measured by the growth rate of the CPI, and financial development is measured by the ratio of private

1 R\&D expenditures are usually deflated by the arithmetic average of hourly labour costs and the GDP deflator (e.g., Coe and Helpman 1995). However, this approach yields implausible movements in real R\&D, since labour earnings show abnormal fluctuations in several developing countries, particularly in Latin America and Africa. Therefore, we have simply used the GDP deflator to express R\&D expenditures in real terms. 


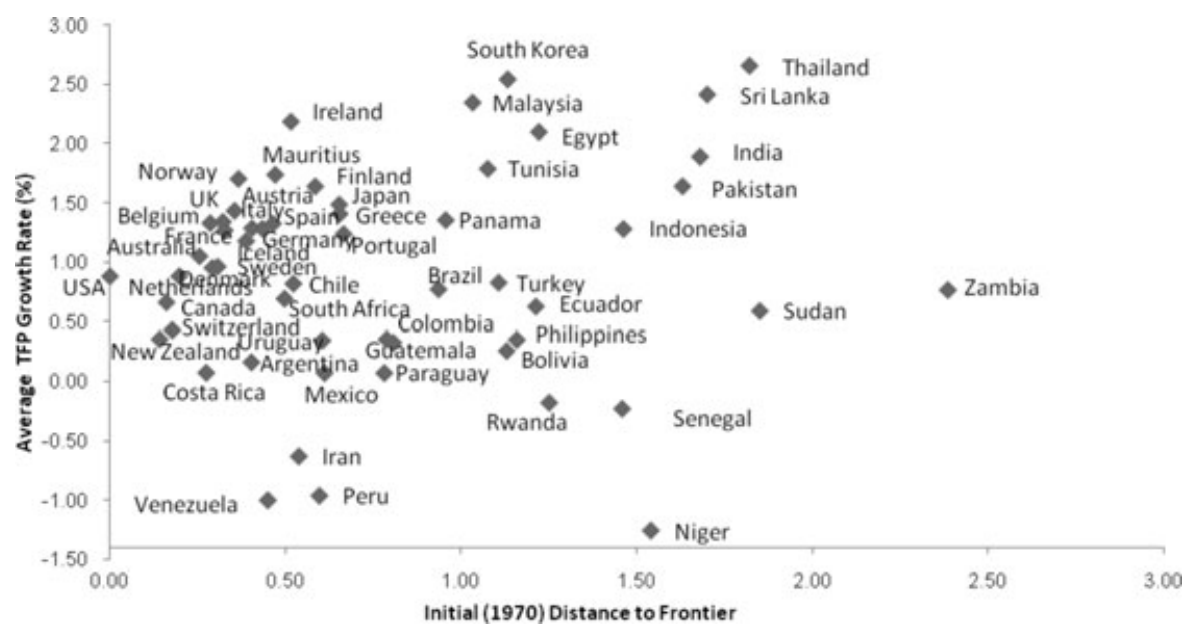

FIGURE 1 Initial distance to the frontier versus average TFP growth (1970-2004)

NOTE: Initial distance to the frontier is measured as the log of the relative TFP gap between the US and sample countries in 1970.

credit to GDP (both are obtained from the World Development Indicators 2009). Following the standard practice, financial development is proxied by the ratio of private credit to GDP (see, e.g., Ang 2008, 2010). Data for distance from the equator are obtained from the 'Finance and the Sources of Growth' database compiled by the World Bank.

Table 1 presents the descriptive statistics for the most important variables used in the regressions. As would be expected, the mean values of all R\&D intensity measures are much larger for OECD countries than for developing countries. According to the Schumpeterian theory, this implies that OECD countries have a larger growth potential than developing countries before the growth effects of the other conditional variables are accounted for. The schooling gap between OECD and developing countries is much smaller than the R\&D intensity gap. The average number of years of schooling of the working-age population in OECD countries is about twice that of the developing countries.

Figure 1 shows a positive relationship between initial (i.e., 1970) distance to the frontier and the average TFP growth rates over the period 1970-2004. The figure provides some evidence of gravitation towards frontier technology countries independently of educational attainment and research intensity. However, the relationship between the two variables is blurred by a high standard deviation. Despite initially being technologically backward, several countries in Latin America (e.g., Venezuela and Peru), Sub-Saharan Africa (e.g., Niger, Rwanda, and Senegal) and Asia (e.g., Iran) appear to be 'growth disasters' with no signs of taking off. On the other hand, the eastern and South-East Asian countries such as South Korea, Thailand, and Malaysia appear to be 'growth miracles,' 


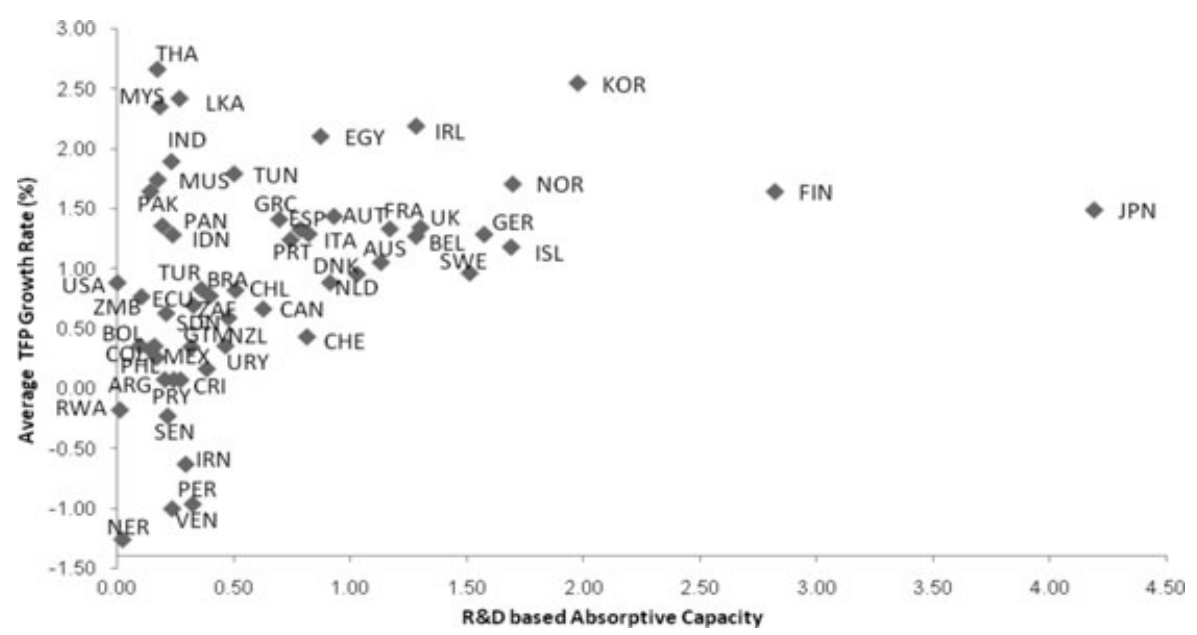

FIGURE 2 R\&D-based absorptive capacity versus average TFP growth

NOTE: R\&D intensity is measured as the average share of scientists and engineers in the total labour force.

with strong growth records over the last few decades. High growth rates have also been observed in some South Asian countries, including India, Pakistan, and Sri Lanka.

Figure 2 displays the relationship between R\&D-based absorptive capacity and the average TFP growth rates, where R\&D intensity is measured by $N / L$. There are some positive correlations between these two variables for higher values of the interaction variable; however, there appears to be no systematic relationship for very low values of the interaction term.

Finally, figure 3 shows a positive relationship between average TFP growth rates and the interaction between educational attainment and the initial distance to the frontier. The high-growth Asian countries have experienced high growth rates in conjunction with initially large distances to the frontier and a reasonably highly educated labour force. The opposite holds true for many African and Latin American countries.

To deal with endogeneity of some of the regressors eq. (4) is estimated using the system GMM estimator of Arellano and Bover (1995) and Blundell and Bond (1998). This technique has been widely used to deal with unobserved heterogeneity and endogeneity biases in estimation. In the presence of heteroscedasticity the system GMM estimator is more efficient than the simple IV estimator (Baum, Schaffer, and Stillman 2003). Furthermore, Bond, Hoeffler, and Temple (2001) show that the system GMM estimator is the most preferred approach for estimation of empirical growth models due to its superior ability in exploiting stationarity restrictions (see also Durlauf, Johnson, and Temple 2005). The system GMM estimator allows for the use of lagged differences and lagged levels 


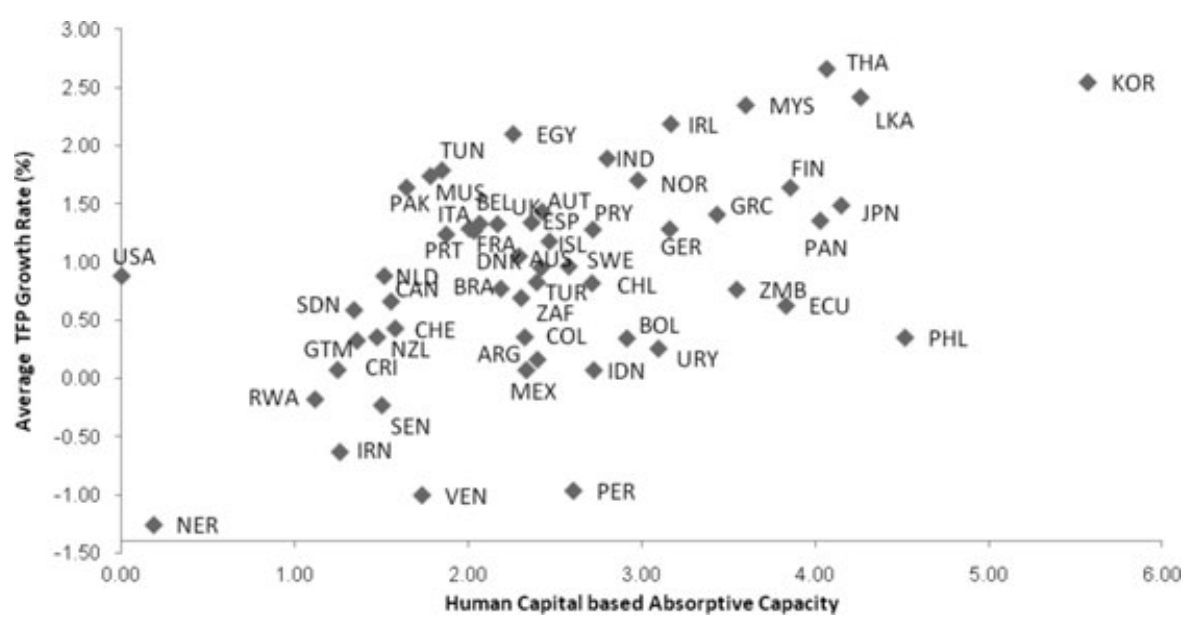

FIGURE 3 Educational attainment-based absorptive capacity versus average TFP growth NOTE: Educational attainment is measured as the average years of schooling of the total population aged 25 and over.

of the explanatory variables as internal instruments. Moreover, the estimator also allows the inclusion of external instruments, providing a convenient way to deal with the issues of endogeneity bias (see Roodman 2009). Consequently, the estimates in this paper are based on the system GMM estimator using internal as well as external instruments.

The following external instruments are used for research intensity, and the interaction between research intensity, and the distance to the frontier: patent protection, effectiveness of legislature, and effective executive. These instruments are multiplied by the distance to the frontier for the interaction between research intensity and the distance to the frontier. They are based on sound economic foundations, are highly correlated with research intensity and its interaction with distance to the frontier, and are orthogonal to the residuals. ${ }^{2}$ Tests for orthogonality are provided in the tables below ('Hansen' and 'difference-inHansen' tests).

Patent protection is important for R\&D because it encourages innovators to work on risky projects where the potential return is higher and reduces uncertainty about possible appropriation. Coe, Helpman, and Hoffmaister (2009), for example, find that strong patent protection is associated with higher levels of total factor productivity, higher returns to domestic R\&D, and larger international R\&D spillovers. Patent protection is measured by the patent rights index of Ginarte and Park (1997). The value of the index is obtained by aggregating

2 The correlation between the external instruments, research intensity, and the distance to the frontier are $0.68-0.75$ for the patent protection index, $0.56-0.67$ for the effectiveness of legislature index, and $0.40-0.44$ for the effective executive index. 
the following five components: extent of coverage, membership in international treaties, duration of protection, absence of restrictions on rights, and statutory enforcement provisions. Each of these components is scored on a scale between 0 and 1.

Effectiveness of legislature and effective executive are also important for R\&D because they express the quality of legislative and political institutions. For effectiveness of legislature, countries that have no legislature, largely ineffective legislatures, and partly effective legislatures receive a score of 0,1 , and 2 , respectively. Countries with effective legislatures are assigned a value of 3 , indicating the possession of significant governmental autonomy by the legislature. Effective executive refers to the individual who is most influential in making decisions regarding a country's internal and external affairs. It is coded based on the following: 1 for monarch, 2 for president, 3 for premier, 4 for military, and 5 for others. These are obtained from Databanks International. ${ }^{3}$

Although many countries have adopted good patent protection frameworks, they can be far from being effective in protecting innovators because of weak legislative and political systems. The ability of a country to implement a law depends on the quality of government agencies such as the judiciary as well as political stability. The higher the efficiency of the judicial system the better the patent protection framework, and the higher is the incentive to innovate. Political stability, accountability of government, and low corruption should also be positively related to patent rights and consequently to innovative activity. For instance, Mauro (1995) shows that investment and innovation are negatively related to corruption and bureaucratic inefficiency. Thus, to ensure that our results are robust to the choice of external instruments, the effectiveness of legislature index is replaced by political rights, civil liberties, polity, ICRG composite index, law and order, or corruption in the regressions. The results of using these instruments are reported in the online appendix and are discussed in the next section. However, our main results continue to hold even after we replace the external instrument effectiveness of legislature with these indexes. This is not surprising, given that the correlation coefficient between effectiveness of legislature and these indexes exceeds 0.7 .

Moreover, to ensure that the empirical results are not driven by outliers, $P / L$ (patent applications over the labour force) is winsorized at the top and bottom $5 \%$ of their distributions, that is, values at the 5 and 95 percentiles are reduced. Winsorizing is not carried out for the regressions in which research intensity is measured by $N / L$ (the ratio of $\mathrm{R} \& \mathrm{D}$ scientists and engineers to the labour force) and $R / Y$ (the share of R\&D expenditure in GDP) because the results are insensitive to whether they are winsorized. 


\section{Estimation results}

Three sets of regressions are considered in this section: unrestricted, $\beta_{3}$ (parameter of the interaction between distance to the frontier and research intensity) restricted to zero, and $\beta_{5}$ (parameter of the interaction between distance to the frontier and educational attainment) restricted to zero. The estimation results using $N / L$ as the indicator of research intensity are reported in table 2. Research intensity enters significantly in the regressions for the whole sample and the OECD sample, but is significant in only one case for the developing countries. The positive effect of R\&D intensity on TFP growth for OECD countries is consistent with the findings of Griffith, Redding, and Van Reenen (2003, 2004), Zachariadis $(2003,2004)$ and Madsen (2008b). The significance of this result is that $R \& D$ has permanent growth effects and that these will remain constant as long as the number of $\mathrm{R} \& \mathrm{D}$ labour is kept at a constant proportion of the labour force. The lower significance of research intensity among the developing countries compared to OECD countries is perhaps not surprising, given that R\&D intensity is too low in developing countries to yield sufficiently large identifying variations in the data or to create positive externalities across a wide range of economic activities, or simply that most innovations are duplications.

The significance of distance to the frontier and its interaction with research intensity and educational attainment varies across country groups. The estimated coefficients of distance to the frontier are statistically significant in all regressions, which is in line with the results of Griffith, Redding, and Van Reenen (2004), Kneller (2005), Kneller and Stevens (2006), and Madsen (2007, 2008a), among others. This finding suggests that TFP growth convergence occurs because of autonomous transfer of foreign technology. The estimated coefficients of the interaction between research intensity and distance to the frontier are significant for the developing countries but are not for OECD countries. The absence of significance for OECD countries is consistent with the estimates of Madsen (2008a). Coupled with the significance of research intensity, these results give very important insights into the role played by research intensity in the developed and the developing countries. R\&D in OECD countries enhances productivity growth but does not enhance the absorptive capacity. In developing countries, by contrast, R\&D may not have significant direct growth effects; however, it enhances the ability of countries to tap into the technology that is developed at the frontiers. In other words, $\mathrm{R} \& \mathrm{D}$ is of an innovative character in OECD countries, but it is predominantly of an imitative character in the developing countries. In both cases, the results give support for the Schumpeterian growth models of Howitt (2000) and Griffith, Redding, and Van Reenen (2003). The results also corroborate the findings of Kneller (2005) for OECD countries.

Most of the estimated coefficients of educational attainment are insignificant. This result is consistent with the findings of Benhabib and Spiegel (1994), 


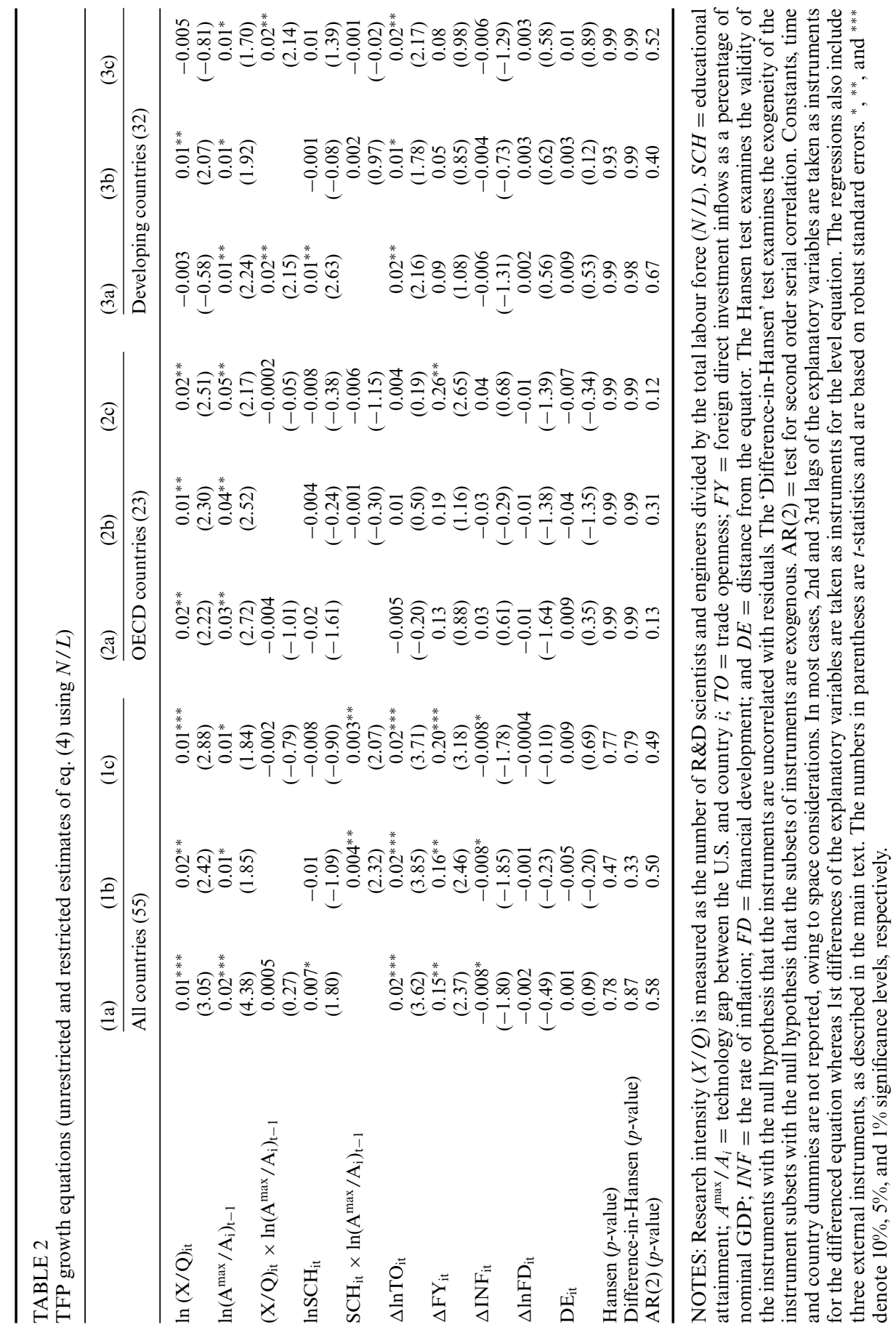


among others, who fail to find a robust direct relationship between educational attainment and growth. Intuitively, it also difficult to see why certain educational categories should induce growth permanently, given that growth is predominantly due to increasing product variety and higher product quality. Most educated people are not employed to carry out R\&D and create new products, and it is hard to see how certain types of education, such as law and arts, would enhance growth.

The estimated coefficients of $S C H_{i t} \ln \left(A^{\max } / A_{i}\right)_{t-1}$ are economically and statistically significant for the overall sample. This supports the hypothesis put forward by Nelson and Phelps (1966) and the empirical findings of Benhabib and Spiegel (1994) and Kneller and Stevens (2006) that an educated labour force increases the absorptive capacity of countries that are behind the technology frontier. However, it is not significant for the sub-samples. When we look at figure 3, these results are not surprising. The figure shows a clear positive relationship for the overall sample; however, when we look closer at the sub-samples the relationship becomes blurred. The low-income countries tend to cluster in the northeast corner of the graph and the developed countries tend to cluster in the southwest corner. This suggests that the results for the sub-samples are influenced by a small sample bias.

Finally, when we consider the effects of the control variables, foreign direct investment as a proportion of GDP, trade openness, and inflation are all significant and carry the right signs in the full sample regressions; however, they are rarely significant in the two separate samples, which may again be a small-sample issue. Almost all of the estimated coefficients of these control variables are insignificant for both country groups. Moreover, we do not find any significant effects of financial development and distance from the equator.

Tables 3 and 4 report the results of estimating eq. (4), where research intensity is measured as the share of R\&D expenditure in total GDP $(R / Y)$ and the number of patent applications divided by the labour force $(P / L)$, respectively. The results are quite similar to those in table 2; however, the interaction between research intensity and the distance to the frontier are statistically insignificant and research intensity is slightly less significant, which may reflect that $(R / Y)$ and $(P / L)$ are less suitable measures of research intensity than $(N / L)$. The problem associated with $(R / Y)$ is that R\&D is deflated by the GDP deflator only because of the erratic behaviour of wages for some countries, as noted in footnote 1 . As wages are increasing more than the GDP deflator, owing to productivity advances over time, increases in real $\mathrm{R} \& \mathrm{D}$ will be exaggerated. The problem associated with $(P / L)$ is that patents are outcomes of innovations, not imitations, and, as such, miss out a significant part of R\&D activity. Despite these measurement problems the results give support for the findings above that R\&D intensity, distance to the frontier, and its interaction with educational attainment are important for growth. 


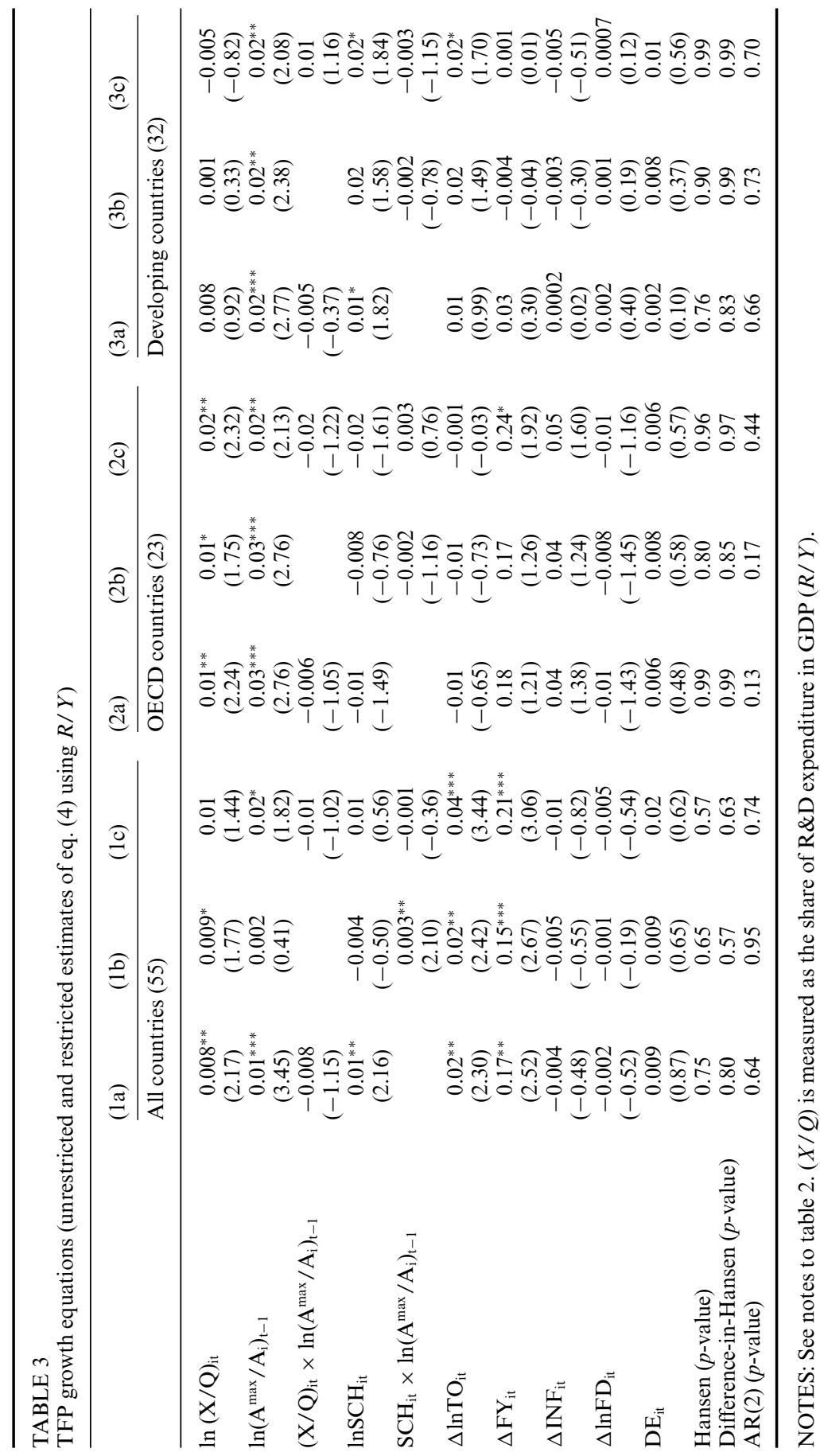




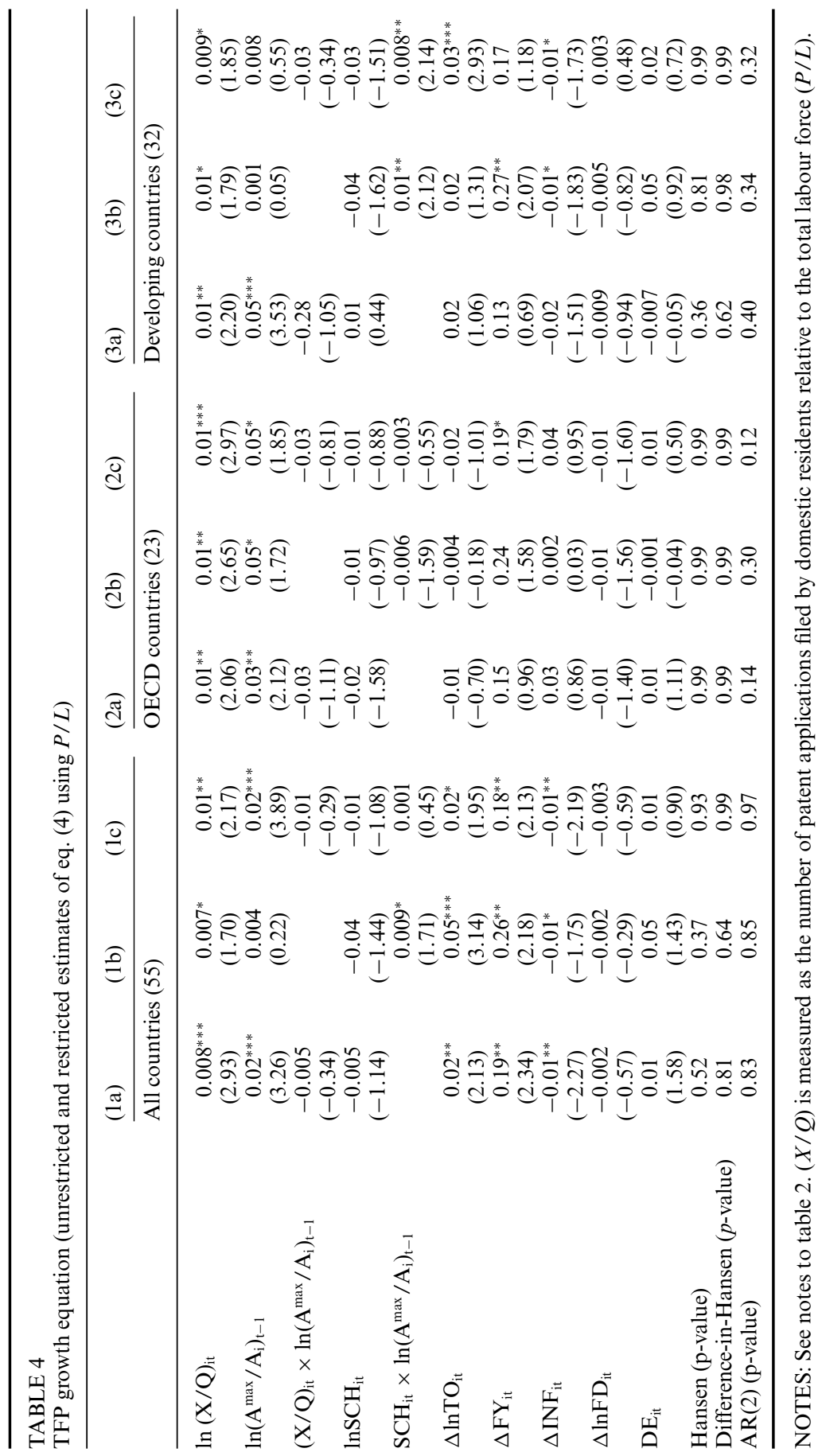




\section{Robustness checks}

A series of sensitivity checks are undertaken in this section to ensure the robustness of the results reported in the previous section to an alternative growth framework, alternative data sets, alternative measurement of key variables, measurement in 10- and 34-year intervals, different functional forms, and other specification issues. The estimation results are not reported here in order to conserve space, but they are provided and discussed in detail in the online appendix. Since our principal results are insensitive to the way in which research intensity is measured, it is computed as the ratio of $\mathrm{R} \& \mathrm{D}$ scientists and engineers to the labour force $(N / L)$. This allows a direct comparison with the key results reported in table 2. Unless otherwise stated, the estimates are based on the system GMM estimator, the same set of instruments is used and the variables are measured in 5 -year intervals. Moreover, the regression approach suggested by Basu, Fernald, and Kimball (2006) is used to ensure that all business cycle influences are filtered out.

\subsection{Alternative growth framework}

The estimates in the previous section are based on the Schumpeterian framework and, as such, do not allow for the possibility that $R \& D$ has only temporary growth effects, following the predictions of the semi-endogenous growth theory of Jones (1995a, b) (see, e.g., Madsen 2008b for discussion). To cater to this, the growth rate of R\&D labour $\left(\Delta \ln X_{i t}\right)$, the growth rate of educational attainment $\left(\Delta \ln S C H_{i t}\right)$, and their interaction with distance to the frontier $\left[\left(\Delta \ln X_{i t}\right) \ln \left(A^{\max } / A_{i}\right)_{t-1}\right.$ and $\left.\left.\left(\Delta \ln S C H_{i t}\right) \ln \left(A^{\max } / A_{i}\right)_{t-1}\right)\right]$ are included as additional regressors in eq. (4). As reported in table A1, contrary to the predictions of the semi-endogenous growth models, in hardly any cases are any of these variables significant. Furthermore, the parameter estimates of the variables considered in eq. (4) are largely unaffected by the inclusion of these additional regressors. Hence, we can conclude that the Schumpeterian growth model is the appropriate framework for the analysis in this paper.

\subsection{Alternative measures of capital stock, educational attainment, and technology gap}

The initial level of capital stock has thus far been computed as $I_{0} /(\delta+g)$. However, $I_{0}$ may be influenced by business cycles and transitional dynamics. To address this concern, the structural initial capital stock is estimated as a linear transformation of the average investment ratio over the period 1970-2004, as detailed in the online appendix. Moreover, our analysis so far has used the average years of schooling of the population aged 25 and over provided by Barro and Lee (2001) as the measure of educational attainment. Since educational attainment plays an important role in this study and is subject to large measurement errors, we also run the regressions using the data set of educational attainment of the 
labour force compiled by Cohen and Soto (2007). They argue that their data set is subject to fewer measurement errors than that of Barro and Lee (2001). Finally, $A^{\mathrm{max}}$ has thus far been measured by the TFP or labour productivity for the US. However, a closer examination of the data reveals that the TFP was indeed higher for Ireland than the US over the period 2001-2004. Moreover, labour productivity in Switzerland was higher than that of the US from 1970-1975 and 1979-1984. Therefore, we provide a sensitivity check in which the technological leader is the country with the highest TFP or labour productivity at any point in time. None of the estimation results obtained in table 2 is significantly affected by these alternative measures of TFP, reinforcing the robustness of these results (see tables A2-A4).

\subsection{Long estimation intervals}

In our empirical estimation, we have used data that are averaged or differenced over 5- year periods to filter out business cycle influences and to mitigate the effects of transitional dynamics. However, the longer is the period over which differences or the averages are taken, the less the estimates are influenced by business cycles and transitional dynamics. Thus, estimates in 10 -year intervals and for the full sample period (1970-2004) are undertaken here. This comes at the cost of an efficiency loss due to a smaller number of available observations. The regression results (see tables A5 and A6) are largely in line with those obtained in table 2, except that the coefficients of R\&D-based absorptive capacity for the full sample period now become insignificant for developing countries, probably because the number of observations is now very low for these countries.

\subsection{The roles of trade openness and foreign direct investment}

Keller (2004) argues that openness to international trade and FDI may work effectively as channels of international technology transfer. Countries that are more open to international trade and FDI are better equipped to take advantage of the technology that is developed in the frontier countries and, therefore, they catch up quicker to the technology frontier. Allowing for these effects on growth yields the following specification (see the online appendix for the derivation): ${ }^{4}$

$$
\Delta \ln A_{i t}=a_{i}+b^{\prime} F_{i t}+c \ln \left(\frac{A_{t-1}^{\max }}{A_{i, t-1}}\right)+d^{\prime} F_{i t} \ln \left(\frac{A_{t-1}^{\max }}{A_{i, t-1}}\right)+v_{i t},
$$

where $F$ is a vector of variables consisting of $\mathrm{R} \& \mathrm{D}$, educational attainment, trade openness, and FDI divided by nominal GDP, and $v_{i t}$ is the stochastic error

4 The framework of Griffith, Redding, and Van Reenen (2000) can also be used to derive Eq. (6). In their model, the equilibrium $R \& D$ is at the point at which the individual is indifferent between intermediate production and R\&D. Eq. (6) can be derived by allowing the potential of imitations through the channels of $F Y$ and $T O$ to be functions of distance to the frontier. 
term. Here, $b^{\prime} F_{i t}$ captures the direct effects and $d^{\prime} F_{i t} \ln \left(A_{t-1}^{\max } / A_{i, t-1}\right)$ captures the indirect effects of $F$ on TFP growth.

The results of estimating this equation give little support for the hypothesis that trade openness and FDI increase the pace at which countries gravitate to the technological frontier (see table A7). The estimated coefficients of the interaction between distance to the frontier and FDI or trade openness are barely significant or not significant at all. The estimated coefficients of other variables are qualitatively very similar to the base case, suggesting that the benefits from technological backwardness can best be exploited by developing countries through enhancing domestic R\&D intensity and investment in education.

\subsection{Other robustness checks}

Finally, the robustness of the results to an alternative estimator (see table A8), to double log form of the absorptive capacity (see table A9), and to alternative control variables and instruments (see tables A10 and A11) is examined. First, the least squares dummy variable (LSDV) estimator for dynamic panel data models (a bias-corrected estimator for the fixed-effects dynamic panel data model that uses dummy variables) overcomes the finite sample bias that the GMM estimator is subject to (see, e.g., Kiviet 1999; Bruno 2005). Second, instead of measuring absorptive capacity by the terms $(X / Q)_{i t} \ln \left(A^{\max } / A_{i}\right)_{t-1}$ and $S C H_{i t} \ln \left(A^{\max } / A_{i}\right)_{t-1}$, they were expressed in a double-log form as $\ln (X / Q)_{i t} \ln \left(A^{\max } / A_{i}\right)_{t-1}$ and $\ln S C H_{i t} \ln \left(A^{\max } / A_{i}\right)_{t-1}$. Third, we consider changes in the GDP deflator, the ratio of $M 3$ to GDP, and landlockness as alternative measures of inflation, financial development, and geographical location, respectively.

Finally, we consider an alternative set of external instruments. Effectiveness of legislature is found to be highly correlated with other widely used institutional variables such as civil liberties, political rights, polity, ICRG composite index, law and order, and corruption (the coefficient of correlations is greater than 0.70 for all the variables). ${ }^{5}$ Therefore, we check the consistency of our results by replacing effective legislature with these institutional variables as alternative external instruments for R\&D. Since the results are highly consistent irrespective of the indicators considered, we only report results based on civil liberties in the online appendix. In all cases, the results are, by and large, very consistent with those reported in table 2, thus reinforcing the evidence that the results in the previous section are fairly robust.

5 Data on political rights and civil liberties are downloaded from http://www.freedomhouse.org/. Data from before 1973 are extrapolated. Data on polity are available for the full sample period and are gathered from the Center for Global Policy (http://globalpolicy.gmu.edu/). The ICRG composite index, law and order, and corruption data obtained from the Political Risk Services (PRS) Group and are available from only 1984. 


\section{Concluding remarks}

The role of R\&D in promoting TFP growth has become increasingly prominent in the empirical growth literature. However, almost all empirical research so far has focused on OECD countries, where evidence of the positive effects of domestic and foreign R\&D on growth has been well documented. Given that developing countries are latecomers, they may well have greater potential for catching up to the technology leader through investment in $R \& D$ and education that facilitates the transfer of foreign technology. This hypothesis is tested in this paper using data for 23 OECD countries and 32 developing countries over the period 1970-2004.

The results show that $R \& D$ intensity, its interaction with distance to the frontier, educational attainment-based absorptive capacity, and technology gap positively influence TFP growth. However, the direct effect of educational attainment is found to have little effect on TFP growth. While the growth effects of research intensity and distance to the frontier generally apply to all country groups, the growth-enhancing effects of educational attainment-based absorptive capacity are limited to the full sample only. Furthermore, R\&D intensity-based absorptive capacity is found to have growth effects only in the developing country sample.

These results provide several important insights. First, educational attainment facilitates convergence to the technological frontier. Second, while the growth effects of R\&D are through innovation in OECD countries, the growth effects of $\mathrm{R} \& \mathrm{D}$ arise mainly through imitation in the developing countries. Third, being far behind the technological frontier does not automatically generate growth. A developing country needs to invest in R\&D to be able to take advantage of the technology that is developed at the frontier.

The findings of this study provide some insights into future growth prospects for both developed and developing countries and policy lessons for the formulation of development strategy. First, the significance of R\&D intensity in explaining TFP growth in OECD countries implies that growth will continue at the present rates for countries at or close to the technology frontier, provided that $\mathrm{R} \& \mathrm{D}$ is kept to a fixed proportion of the number of product lines. Second, developing countries that invest in $\mathrm{R} \& \mathrm{D}$ will continue to grow, owing to the positive growth effects of the interaction between distance to the frontier and research intensity. When research-intensive developing countries eventually move closer to the frontier, research intensity will take over as the main engine of growth as the economies evolve from being just imitators to being both imitators and innovators.

\section{References}

Abromovitz, M. (1986) 'Catching up, forging ahead, and falling behind,' Journal of Economic History 46, 386-406 
Aghion, P., and P. Howitt (1992) 'A model of growth through creative destruction,' Econometrica 60, 323-51

- (1998) Endogenous Growth Theory, (Cambridge, MA: MIT Press)

- (2005) 'Growth with quality-improving innovations: an integrated framework,' in Handbook of Economic Growth, ed. P. Aghion and S.N. Durlauf (Amsterdam: Elsevier)

Aghion, P., P. Howitt, and D. Mayer-Foulkes (2005) 'The effect of financial development on convergence: theory and evidence,' Quarterly Journal of Economics 120, 173222

Andrés, J., and I. Hernando (1997) 'Does inflation harm economic growth? Evidence from the OECD,' NBER Working Paper No. 6062

Ang, J.B. (2008) 'A survey of recent developments in the literature of finance and growth,' Journal of Economic Surveys 22, 536-76

- (2010) 'Finance and inequality: the case of India,' Southern Economic Journal 76, 738-61

Ang, J.B., and W.J. McKibbin (2007) 'Financial liberalization, financial sector development and growth: evidence from Malaysia,' Journal of Development Economics 84, 215-33

Arellano, M., and O. Bover (1995) 'Another look at the instrumental variable estimation of error-components models,' Journal of Econometrics 68, 29-51

Barro, R.J., and J.W. Lee (2001) 'International data on educational attainment: updates and implications,' Oxford Economic Papers 53, 541-63

Basu, S., J.G. Fernald, and M.S. Kimball (2006) 'Are technology improvements contractionary?' American Economic Review 96, 1418-48

Baum, C.F., M.E. Schaffer, and S. Stillman (2003) 'Instrumental variables and GMM: estimation and testing,' Stata Journal 3, 1-31

Benhabib, J., and M.M. Spiegel (1994) 'The role of human capital in economic development: evidence from aggregate cross-country data,' Journal of Monetary Economics $34,143-73$

- (2005) 'Human capital and technology diffusion,' in Handbook of Economic Growth, ed. P. Aghion and S. Durlauf (Amsterdam: Elsevier)

Blundell, R., and S. Bond (1998) 'Initial conditions and moment restrictions in dynamic panel data models,' Journal of Econometrics 87, 115-43

Bond, S.R., A. Hoeffler, and J. Temple (2001) 'GMM estimation of empirical growth models,' Centre for Economic Policy Research Discussion Paper No. 3048

Bosworth, B., and S.M. Collins (2003) 'The empirics of growth: an update,' Brookings Papers on Economic Activity 2, 180-200

Bruno, G.S.F. (2005) 'Approximating the bias of the LSDV estimator for dynamic unbalanced panel data models,' Economics Letters 87, 361-66

Coe, D.T., and E. Helpman (1995) 'International R\&D spillovers,' European Economic Review 39, 859-97

Coe, D.T., E. Helpman, and A.W. Hoffmaister (1997) 'North-South R\&D spillovers,' Economic Journal 107, 134-49

- (2009) 'International R\&D Spillovers and Institution,' European Economic Review 53, $723-41$

Cohen, D., and M. Soto (2007) 'Growth and human capital: good data, good results,' Journal of Economic Growth 12, 51-76

Cohen, W.M., and D.A. Levinthal (1989) 'Innovation and learning: the two faces of R\&D,' Economic Journal 99, 569-96

Durlauf, S., P. Johnson and J. Temple (2005) 'Growth econometrics,' in Handbook of Economic Growth, ed. P. Aghion and S. Durlauf (Amsterdam: North-Holland)

Easterlin, R.E. (1981) 'Why isn't the whole world developed?' Journal of Economic History 41, 1-19 
Eaton, J., and S. Kortum (1999) 'International technology diffusion: theory and measurement,' International Economic Review 40, 537-70

Engelbrecht, H.J. (1997) 'International R\&D spillovers, human capital and productivity in OECD economies: an empirical investigation,' European Economic Review 41, 1479-88

Fagerberg, J. (1994) 'Technology and international differences in growth rates,' Journal of Economic Literature 32, 1147-75

Fischer, S. (1993) 'The role of macroeconomic factors in growth,' Journal of Monetary Economics 32, 485-512

Gerschenkron, A. (1962) Economic Backwardness in Historical Perspective (Cambridge, MA: Belknap Press of Harvard University Press)

Ginarte, J., and W. Park (1997) 'Determinants of patent rights: a cross-national study,' Research Policy 26, 283-301

Griffith, R., S. J. Redding and J. Van Reenen (2000) 'Mapping the two faces of R\&D: productivity growth in a panel Of OECD industries,' CEPR Discussion Paper 2457

- (2003) 'R\&D and absorptive capacity: theory and empirical evidence,' Scandinavian Journal of Economics 105, 99-118

- (2004) 'Mapping the two faces of R\&D: productivity growth in a panel of OECD industries,' Review of Economics and Statistics 86, 883-95

Griliches, Z. (1990) 'Patent Statistics as economic indicators: a survey,' Journal of Economic Literature 28, 1661-707

Ha, J., and P. Howitt (2007) 'Accounting for trends in productivity and R\&D: a Schumpeterian critique of semi-endogenous growth theory,' Journal of Money, Credit and Banking 39, 733-74

Hobday, M. (2003) 'Innovation in Asian industrialization: a Gerschenkronian perspective,' Oxford Development Studies 31, 293-314

Howitt, P. (2000) 'Endogenous growth and cross-country income differences,' American Economic Review 90, 829-46

- (2005) 'Health, human capital and economic growth : a Schumpeterian perspective,' in Health and Economic Growth: Findings and Policy Implications, ed. G. LopezCasasnovas, B. Rivera, and L. Currais (Cambridge, MA: MIT Press)

Hu, A.G.Z., G.H. Jefferson, and Q. Jinchang (2005) 'R\&D and technology transfer: firmlevel evidence from Chinese industry,' Review of Economics and Statistics 87, 780-86

IMF (2007) International Financial Statistics 2007 (CD ROM) (Washington, DC: IMF and World Bank)

Jaffe, A.B., and K. Palmer (1997) 'Environmental regulation and innovation: a panel data study,' Review of Economics and Statistics 79, 610-19

Jones, C. (1995a) 'R\&D based models of economic growth,' Journal of Political Economy $103,759-84$

- (1995b) 'Time Series tests of endogenous growth models,' Quarterly Journal of Economics $110,495-525$

Keller, W. (2002a) 'Geographic localization and international technology diffusion,' American Economic Review 92, 120-42

- (2002b) 'Trade and the transmission of technology,' Journal of Economic Growth 7, $5-24$

- (2004) 'International technology diffusion,' Journal of Economic Literature 42, $752-$ 82

Kiviet, J.F. (1999) 'Expectation of expansions for estimators in a dynamic panel data model; some results for weakly exogenous regressors,' in Analysis of Panel Data and Limited Dependent Variables, ed. C. Hsiao, K. Lahiri, L.-F. Lee, and M.H. Pesaran (Cambridge: Cambridge University Press)

Kneller, R. (2005) 'Frontier technology, absorptive capacity and distance,' Oxford Bulletin of Economics and Statistics 67, 1-23 
Kneller, R., and P.A. Stevens (2006) 'Frontier technology and absorptive capacity: evidence from OECD manufacturing industries,' Oxford Bulletin of Economics and Statistics $68,1-21$

Madsen, J.B. (2007) 'Technology spillover through trade and TFP convergence: 135 years of evidence for the OECD countries,' Journal of International Economics 72, 464-80

- (2008a) 'Economic growth, TFP convergence and the world export of ideas: a century of evidence,' Scandinavian Journal of Economics 110, 145-67

- (2008b) 'Semi-endogenous versus Schumpeterian growth models: testing the knowledge production function using international data,' Journal of Economic Growth 13, 1-26

- (2009) 'Trade barriers, openness, and economic growth,' Southern Economic Journal $76,397-418$

Madsen, J.B., and P. Davis (2006) 'Equity prices, productivity growth and 'the new economy', Economic Journal 116-513

Madsen, J.B., S. Saxena, and J.B. Ang (2009) 'The Indian growth miracle and endogenous growth,' Journal of Development Economics, forthcoming. (doi:10.1016/ j.jdeveco.2009.06.002)

Mauro, P. (1995) 'Stock markets and growth: a brief caveat on precautionary savings,' Economics Letters 47, 111-16

Nelson, R.R., and E.S. Phelps (1966) 'Investment in humans, technological diffusion, and economic growth,' American Economic Review 56, 69-75

Rodrik, D., A. Subramanian, and F. Trebbi (2004) 'Institutions rule: the primacy of institutions over geography and integration in economic development,' Journal of Economic Growth 9, 131-65

Romer, P.M. (1990) 'Endogenous technological change,' Journal of Political Economy 98, S71-102

Roodman, D. (2009) 'How to do xtabond2: an introduction to difference and system GMM in Stata,' The Stata Journal 9, 86-136

Savvides, A., and M. Zachariadis (2005) 'International technology diffusion and the growth of TFP in the manufacturing sector of developing economies,' Review of Development Economics 9, 482-501

UNESCO (various issues) Statistical Yearbook,

Verspagen, B. (1991) 'A new empirical approach to catching up or falling behind,' Structural Change and Economic Dynamics 2, 359-80

WDI (2007) World Development Indicators 2007 (CD ROM) (Philadelphia: World Bank)

World Intellectual Property Organization (WIPO) (2007) WIPO Patent Report: Statistics on Worldwide Patent Activity

$\mathrm{Xu}, \mathrm{B}$. (2000) 'Multinational enterprises, technology diffusion, and host country productivity growth,' Journal of Development Economics 62, 477-93

Zachariadis, M. (2003) 'R\&D, innovation, and technological progress: a test of the Schumpeterian framework without scale effects,' Canadian Journal of Economics 36, 566-86

Zachariadis, M. (2004) 'R\&D-induced growth in the OECD?' Review of Development Economics 8, 423-39 